\title{
Jogo e protagonismo da criança na educação infantil
}

\author{
Lívia Carvalho de Assisi, André da Silva Melloii, Amarílio \\ Ferreira Neto iii, Wagner dos Santosiv \& Omar Schneider ${ }^{\mathrm{v}}$ \\ Universidade Federal do Espírito Santo, Brasil
}

\begin{abstract}
Resumo
Neste artigo, analisamos os usos e as apropriações que as crianças fazem do jogo em um Centro de Educação Infantil de Vitória/ES/Brasil, para compreender o protagonismo que elas estabelecem nas relações com essa manifestação cultural. Para tanto, utilizamos os Estudos com o Cotidiano como pressuposto teórico-metodológico. Os dados foram produzidos por meio de narrativas e observação participante, durante quatro meses de inserção na escola. As análises revelam que o jogo é vivenciado pelas crianças em situações espontâneas e, sobretudo, nas aulas de Educação Física. No primeiro caso, as crianças organizam suas próprias práticas, com predomínio dos jogos simbólicos; já nas aulas, elas agem taticamente, alterando os jogos propostos pelo professor segundo os seus interesses e necessidades. Em ambos os casos, a perspectiva sócio-histórica, de Vygotsky, e o conceito de consumo produtivo, de Certeau, evidenciaram a produção cultural das crianças nas relações que estabelecem com o jogo, denotando o seu protagonismo.
\end{abstract}

Palavras-chave

Jogo; Educação Física; Educação infantil; Protagonismo

\section{Introdução}

Historicamente, a escola tem lançado sobre as crianças um olhar que as concebe como seres incompletos e incapazes, que precisam ser 
'preenchidos' pelo adulto, para que possam alcançar a sua maturidade (Dahlberg, Moss, \& Pence, 2003). Nessa perspectiva, elas são sempre um 'vir a ser', constituindo-se como "[...] alvo do tratamento, da orientação ou da acção pedagógica dos mais velhos" (Sarmento, 2008, p. 19). As crianças são representadas pela sua negatividade, ou seja, por um conjunto de procedimentos que negam as suas ações, capacidades e autoria, sob o argumento de que não têm condições de tomar decisões e pensar por si mesmas.

Nesse sentido, as práticas pedagógicas são apropriadas pelas escolas de forma utilitarista, para sanar as faltas e ausências que as crianças supostamente apresentam. Orientadas por outros pressupostos, em especial pelos preconizados pela Sociologia da Infância (Sarmento, 2008), instituições de Educação Infantil têm buscado ressignificar essa racionalidade 'adultocêntrica', colocando "[...] as crianças como actores sociais nos seus mundos de vida, e a infância como categoria social do tipo geracional, socialmente construída" (Sarmento, 2008, p. 22). Essa perspectiva atribui protagonismo às crianças, considerando-as como coprodutoras de cultura e de conhecimento, substituindo a visão que as concebe como seres passivos por uma representação de praticante (Certeau, 1994), que possui interesses, expectativas e necessidades específicas de sua geração. $O$ desafio para a efetivação dessa perspectiva pedagógica é de natureza didáticometodológica, ou seja, está circunscrito nas possibilidades de materialização de uma práxis docente que dê voz e vez às crianças nos processos de ensinoaprendizagem.

Ao considerarmos que o brincar é uma das principais linguagens que a criança utiliza na sua relação com o meio e com os outros (Mello et al., 2012; Neira, 2008; Sayão, 2002), o jogo se constitui em uma forma privilegiada para superar a lógica adultocêntrica que prevalece na escola, principalmente aquela destinada a escolarização das crianças de zero a cinco anos de idade. Contudo, para que isso ocorra, é preciso conceber o jogo não apenas como um meio para aquisição de conteúdos, mas como um espaço-tempo que potencialize as produções culturais das crianças nas relações sociais que estabelecem entre si e com os adultos.

Referenciado em experiências pedagógicas concretas, vivenciadas por duas turmas de crianças na faixa etária entre cinco e seis anos de idade 
(Grupo 5 e Grupo 6, respectivamente), de um Centro Municipal de Educação Infantil (CMEI) de Vitória/Espírito Santo/Brasil, este estudo objetiva analisar os usos e as apropriações que as crianças fazem do jogo no cotidiano escolar. Busca, ainda, compreender os pontos de convergência e os de divergência entre as expectativas do professor e as das crianças na apropriação do jogo, focalizando os desafios e as possibilidades para que o protagonismo infantil seja considerado na intervenção pedagógica empreendida pelo professor.

\section{Delineamento teórico-metodológico}

Este estudo tem como delineamento teórico-metodológico os Estudos com o Cotidiano (Alves, 2008; Certeau, 1994; Ferraço, 2008), em que a prática pedagógica assume a centralidade nos processos interpretativos empreendidos na compreensão dos saberes produzidos pelos professores e pelas crianças. Ferraço (2008), destaca a importância da prática nesse tipo de estudo e afirma que "[...] é na e pela prática cotidiana do homem comum que se produzem as condições de transformação de impossível em possível" ( $p$. 27). A prática é o foco das pesquisas com o cotidiano. Por meio dela, é possível perceber as relações entre o concebido, o percebido e o vivido.

Ao "mergulharmos" no cotidiano escolar, analisamos como o professor e as crianças lidam com o jogo nos diferentes espaços e tempos escolares. Ao considerarmos que o jogo é uma manifestação cultural polissêmica, diferentes sentidos e significados incidem sobre a sua prática na escola. Ancorados pelo conceito de consumo produtivo, proposto por Certeau (1994), que afirma que os indivíduos não consomem passivamente os produtos culturais que lhe são oferecidos, buscamos compreender os usos e as apropriações que o professor e as crianças fazem do jogo no contexto compartilhado.

As práticas geradas pelo consumo produtivo se referem a maneiras, artes e modos de fazer de cada pessoa, a partir de uma situação vivenciada. Com isso, compreendemos, por meio das manifestações (usos e apropriações) observadas das crianças nos jogos, que esses momentos se consolidam como indícios para perceber o protagonismo infantil, já que cada criança, ao jogar, se manifesta de uma maneira particular. 
Esses usos e apropriações são geradores do consumo produtivo, que é originário das maneiras e das artes de fazer que os praticantes fazem do lugar de poder. Sabendo que existem relações de poder no cotidiano escolar, utilizamos os conceitos de estratégia e tática, também propostos por Certeau (1994). A estratégia se refere ao "lugar da autoridade", é aquilo que está instituído nas relações assimétricas de poder. Já a tática se reporta às maneiras de fazer, nos tempos e espaços instituídos pelo lugar de poder, pois, nas palavras do próprio Certeau (1994):

[...] a tática depende do campo do outro. Joga lance a lance, na busca de auferir ganho. Pode-se dizer que a tática está em movimento permanente (capta no voo) para conferir legitimidade no campo do outro, o que the garante um nãolugar estratégico (pp. 46-47).

Consideramos como táticas os usos e as apropriações que as crianças fazem do jogo nas aulas de Educação Física e em outros espaços e tempos da Educação Infantil, os sentidos que elas imprimem a essa manifestação cultural quando jogam, assim como as ações criativas que produzem. Almejamos, com isso, evidenciar as táticas utilizadas pelas crianças, para que, na perspectiva do protagonismo infantil (Sarmento, 2008), elas possam se constituir em novas estratégias de intervenção no contexto compartilhado.

Para alcançar os objetivos propostos, mergulhámos, durante quatro meses (setembro a dezembro de 2011), no cotidiano de um CMEI de Vitória/Espírito Santo/Brasil. Participámos dos planejamentos do professor dinamizador de Educação Física e de suas aulas, destinadas aos Grupos 5 e 6, e também de momentos caracterizados como os de não-aula, como recreio, atividades do parquinho, dentre outros. Optamos por dar visibilidade aos Grupos 5 e 6 por possuírem uma linguagem verbal mais articulada, facilitando, assim, a interpretação das suas narrativas.

Focalizamos outras linguagens, especialmente a corporal, pois, por meio dela, a criança se expressa e produz conhecimentos. De acordo com Gomes e Baumel (2009), "O movimento expressivo marca a experiência vivida, em ação, e nos possibilita criar sentidos e significados [...]" (p. 4). Considerando que este estudo concebe as crianças como sujeitos de direitos e que um dos objetivos da pesquisa é evidenciar as produções infantis materializadas no jogo, buscando subsídios para orientar os processos de intervenção mediados por essa manifestação cultural, faz-se necessário 
compreender os modos de 'dizer' da criança, para incluí-la como protagonista de suas práticas pedagógicas.

Privilegiamos as narrativas produzidas pelas crianças e pelo professor. Em relação às crianças, entendemos que nem todas as narrativas são textualizadas e verbalizadas, elas também estão presentes no corpo: "[...] nuestro corpo tambiem cuenta história y las narrativas tambiem estám corporeizadas [...]" (Samaniego, Devis-Devis, Smith, \& Sparkes, 2011, p. 24). Em relação ao professor, a narrativa proporcionou o diálogo entre ele e nós, pesquisadores. Buscamos compreender os sentidos que ele atribui à sua prática pedagógica. De acordo com Silva e Maia (2010), "[...] a narração de si revela muito mais que os acontecimentos circunscritos, informando também as implicações da pessoa com a sua experiência, isto é, a forma como ela vê, sente, avalia, julga, compreende e representa sua história de vida" (p. 7).

As narrativas das crianças, do professor de Educação Física e da observação participante foram sistematizadas em diário de campo e portfólios. No processo interpretativo, aproximamos as narrativas advindas dessas diferentes fontes, considerando o contexto sociointeracional em que foram produzidas e as matrizes teórico-epistemológicas que deram suporte a este estudo: Sociologia da Infância, Psicologia Sócio-Histórica e os Estudos com o Cotidiano.

Ao articularmos o campo da Sociologia da Infância com a Psicologia Sócio-Histórica e os Estudos com o Cotidiano, compreendemos, assim como Sarmento (2013), que esse campo, isoladamente, não conseguirá "[...] cumprir o seu programa se não se abrir determinantemente a um trabalho teórico interdisciplinar, que contribua para impedir uma visão fragmentária de criança [...]" (p. 20). Dentre as contribuições de outras disciplinas científicas para a compreensão da infância, este autor destaca os postulados da Psicologia Sócio-Histórica, de Lev Semyonovitch Vygotsky, especialmente no que concerne ao processo sociocultural de desenvolvimento humano, em que o papel do "outro", da cultura, se configura como pressuposto fundamental. Nas análises empreendidas neste estudo, constatamos que as produções culturais relativas ao jogo aconteceram nas interações sociais, especialmente entre a "cultura de pares", denotando que o protagonismo infantil se manifesta, sobretudo, na ação coletiva. O papel do "outro" também se revela na zona de desenvolvimento proximal, em que as mediações promovidas 
pelos sujeitos mais experientes, em especial pelo professor, contribuem para que as crianças no jogo ajam de maneira mais avançada em relação ao seu nível de desenvolvimento real.

Já os Estudos com o Cotidiano contribuíram para perceber a prática como espaçotempo de manifestação do protagonismo infantil. Para Certau (1994), as práticas cotidianas apresentam duas dimensões que denotam o protagonismo das crianças: a ética e a estética. A primeira explicita a vontade histórica de existir das crianças, a recusa à identificação com a ordem ou a lei imposta pelos adultos. Nesse sentido, as práticas cotidianas são defesas para a vida, em que os infantis agem astuciosamente para fazer valer os seus interesses, necessidades e expectativas. Já a segunda revela uma estética da recepção, pois as crianças não absorvem passivamente os bens culturais que Ihes são ofertados. Como consumidoras produtivas, elas imputam as suas marcas e criações a esses bens.

O diálogo entre essas perspectivas teóricas, aparentemente conflitantes, demarca o esforço em compreender a infância na sua complexidade e pluralidade. Para Sarmento (2013), "[...] é possível realizar pesquisa pluriparadigmática sem se cair em incongruência" (p. 27) e sinalizar para a possibilidade de convergência de teorias de orientações críticas e interpretativas, como as utilizadas nesta pesquisa. A confluência de diferentes matrizes teóricas e epistemológicas potencializa a formulação de sínteses integradoras, geradas a partir de um quadro interpretativo mais amplo, favorecendo a construção de metateorias que buscam romper com a visão fragmentada e reduzida da infância.

\section{Do consumo produtivo ao protagonismo infantil: 0 jogo como possibilidade}

Analisamos os usos e apropriações que as crianças e o professor de Educação Física fazem do jogo no cotidiano de um CMEl. Optamos por dar visibilidade ao CMEl Alegria, pois, nessa instituição, o jogo é um conteúdo privilegiado na intervenção pedagógica do professor nas aulas de Educação Física. O CMEI, que foi inaugurado no ano de 1996, conta com um amplo espaço e com uma boa infraestrutura. O Centro Municipal recebe crianças de Santa Marta e Andorinhas, bairros periféricos da grande Vitória/Espírito Santo/Brasil. 
Os dados produzidos evidenciam que o jogo foi vivenciado em duas dimensões: em momentos espontâneos, em que há a presença do adulto, entretanto ele não intervém na organização das atividades realizadas pelas crianças; e em momentos de aula de Educação Física, em que há a presença e o direcionamento do professor.

Quando as atividades são realizadas em momentos espontâneos, como na hora do parquinho e do recreio, é possível perceber a predominância dos jogos simbólicos. De acordo com a classificação proposta por Caillois (1990), os jogos caracterizados pelo predomínio da fantasia e da imaginação são denominados de mimicry. Neles, os jogadores internalizam papéis sociais e situações que diferem da realidade imediata em que estão inseridos.

A denominação proposta por Caillois (1990) está associada ao jogo de faz-de-conta, discutido por Vygotsky (1994). Para esse autor, mais do que uma fonte de prazer, o jogo de faz-de-conta contribui para o desenvolvimento da capacidade de representar simbolicamente a realidade. Crianças que estão na Educação Infantil se encontram em uma fase do desenvolvimento em que "[...] a imaginação é um processo psicológico novo [...] representa uma forma especificamente humana de atividade consciente, não estando presente na consciência de crianças muito pequenas" (Vygotsky, 1994, p. 122).

Para Vygotsky (1994), essas brincadeiras contribuem para o desenvolvimento da criança, pois separam objeto de significado e impulsionam o alargamento da zona de desenvolvimento proximal. No início do processo de desenvolvimento infantil, o comportamento da criança é determinado pelas condições do ambiente, ou seja, por aquilo que está no seu campo perceptual. Dessa forma, os objetos ditam o que ela tem que fazer, pois possuem uma força motivadora. Já nas crianças com idade verbal, o pensamento está separado dos objetos e a ação é mediada por representações e não pelas "coisas em si". Nessa fase, elas passam por um período de transição e aprendem a agir numa esfera simbólica (Vygotsky, 1994). Esse percurso de transição ocorre por um longo período, pois é difícil para a criança separar o significado do objeto, ou seja, operar com signos. Durante o desenvolvimento do processo de operar com signos, é comum observarmos, nos jogos, a utilização de objetos semelhantes ao real. Os registros abaixo, extraídos do diário de campo, demonstram situações em que os significados dos objetos foram substituídos por representações formuladas no jogo: 
[...] observamos algumas crianças sobre a borda do brinquedo [barco de plástico] e perguntamos: 'De que vocês estão brincando?'. Uma criança respondeu: 'Estamos surfando na prancha'[...] (Diário de Campo [DC], 7-112011 - Grupo 5).

[...] naquele momento, estava acontecendo uma festa. Participamos da festa, quando a pesquisadora comentou: 'Quero comer um bolo'. Uma criança pegou umas folhas redondas e falou: 'É de mentirinha, tia' [...] (DC, 4-11-2011 - Grupo 5).

Segundo Freire (2002), o caráter subjetivo predomina no jogo, porém essa subjetividade estabelece relação com a realidade. Normalmente, o objeto apresenta alguma relação com aquilo que é representado, por exemplo, as folhas redondas com o bolo. Durante os jogos, as crianças transitam por situações imaginárias; entretanto permanecem ligadas à realidade ao escolherem para brincar objetos que se assemelham, seja na forma, seja na função, ao que está sendo representado.

Além de separar objeto de significado, os jogos simbólicos também se caracterizaram pela imitação de papéis sociais, como demonstram as seguintes narrativas:

[...] observamos quatro crianças brincando, uma menina representava a mãe, um menino o pai, outro menino o filho e uma menina era uma gatinha [...] (DC, 3-10-2011 - Grupo 6).

[...] uma criança chegou próximo à pesquisadora e falou: 'Você quer suco de quê?'. Ela respondeu: 'De manga'. Ele saiu correndo, foi ao seu restaurante, que ficava localizando na parte superior do escorregador, preparou o suco e o trouxe para a pesquisadora [...] (DC, 7-11-2011 - Grupo 5).

As ações das crianças, nessas brincadeiras, geralmente se submetem às condutas/ regras típicas das situações representadas. São justamente as regras implícitas nas brincadeiras que fazem com que elas se comportem de forma mais avançada do que aquela habitual para sua idade. Elas internalizam papéis sociais que estão além do seu nível de desenvolvimento real, operando em uma zona que Vygostky (1994) denominou de "desenvolvimento proximal":

Ela é a distância entre o nível de desenvolvimento real, que se costuma determinar através da solução independente de problemas, e o nível de desenvolvimento potencial, determinado através da solução de problemas sob a orientação de um adulto ou em colaboração com companheiros mais capazes (p. 112). 
Na incorporação de papéis sociais, mediada pelo jogo simbólico, não há apenas uma reprodução mecânica do que acontece na vida social. Ocorre um processo de apropriação, tornando o momento da brincadeira como um espaço em que a realidade é pensada, transformada e reinventada, sob os seus próprios modos de ser (Borba, 2009).

Nos tempos e espaços espontâneos, observamos que as crianças ressignificam os jogos e também os brinquedos dispostos no pátio. De acordo com Certeau (1994), os indivíduos não consomem passivamente os produtos culturais que lhe são oferecidos, pois há maneiras e artes de se apropriar que produzem diversos sentidos e significados. O fragmento a seguir, extraído dos registros da observação participante, evidencia os diferentes usos e apropriações do jogo "pega-pega", realizado pelas crianças:

[...] eles estavam brincando de Chapeuzinho Vermelho. No começo, a brincadeira estava bem bagunçada, até que uma aluna pediu para todo mundo sentar que ela iria organizar os personagens. Algumas crianças não queriam sentar, mas ela falou: 'Quem não sentar não vai brincar' e todas sentaram. Cada criança representou algum personagem. O personagem que fosse o lobo seria o pegador, tendo em vista que, na história infantil, o lobo come a vovó e depois se veste de vovozinha. Esse lobo, então, seria a vovozinha disfarçada, que ficaria deitada dentro de casa. O espaço onde aconteceu esse jogo dispõe de vários brinquedos, sendo um deles uma casa. Todos os personagens entravam na casa. A vovó (lobo) permanecia deitada no chão; ao sinal de uma criança, neste caso da aluna que organizou os personagens, todos saíam correndo e o lobo corria atrás. Depois que todos fossem pegos pelo lobo, eles sentavam e organizavam novamente os personagens [...] (DC, 7-11-2011 Grupo 6).

Evidenciamos que as crianças relacionaram um conto infantil (Chapeuzinho Vermelho) com o jogo tradicional "pega-pega". Elas propuseram um novo sentido à brincadeira que, de acordo com Vygotsky (1994), converge com as peculiaridades do desenvolvimento infantil, já que a imaginação emerge durante o jogo. Por meio desse fragmento, também analisamos as relações de poder que atravessam os diálogos estabelecidos pelas crianças. Institucionalmente, elas estão em um mesmo nível, todas são iguais; entretanto, durante a brincadeira, a criança que havia dado a ideia daquela atividade se colocou como autoridade, ao falar: "Quem não sentar, não vai brincar".

Ancorados em Certeau (1994), percebemos que, nesse momento, ela usou da autoridade concedida pelos pares e agiu de maneira estratégica, 
consolidando-se como aquela que detinha poder para determinar como seria o jogo. Normalmente, a invenção de novas brincadeiras parte das mesmas crianças, que possuem alguma forma de ascensão sobre as outras. No caso do jogo relatado, observamos que a menina que coordenava as ações possuía uma linguagem verbal articulada, que a qualificava para organizar os colegas e estabelecer regras para que o jogo acontecesse. A estratégia não se aprisiona a um lugar fixo, mas se configura de acordo com o contexto de produção e a relação que mantém com o poder. Apesar de as crianças pertencerem à mesma categoria geracional, a infância, as relações que estabelecem se configuram em relações de poder.

Muitos brinquedos são fabricados com o intuito de serem utilizados de uma determinada maneira. O espaço do CMEI possui uma série de brinquedos que, intencionalmente, já ditam o modo como a criança deve se comportar, mas o fragmento apresentado a seguir evidencia a criatividade das crianças frente aos usos do escorregador:

[...] neste dia, por exemplo, o escorregador, na parte superior, representou o restaurante para o Felipe. Para os meninos, que estavam com as peças de dinheiro, a parte inferior do brinquedo serviu como esconderijo da brincadeira de polícia e ladrão. Eles subiam e desciam de diferentes maneiras e por diversos lugares do brinquedo [...] (DC, 7-11-2011 - Grupo 5).

Apreendemos que a criança assina/ demarca a sua existência como autora, ao utilizar maneiras e artes de fazer, em que atribui diferentes sentidos e significados a suas práticas lúdicas. Entretanto, essa é uma ação tática, que não confere à criança, em relação à escola, um lugar de autoria, pois a ação de produzir diferentes sentidos e significados nas brincadeiras não é registrada. Não existe um local, um espaço em que se possa demarcar aquilo que ela faz/cria nos momentos espontâneos. Como aponta Certeau (1994):

A 'fabricação' que se quer detectar é uma produção, uma poética - mas escondida, porque ela se dissemina nas regiões definidas e ocupadas pelos sistemas da produção (televisiva, urbanística, comercial, etc.) e porque a extensão sempre mais totalitária desses sistemas não deixa aos 'consumidores' um lugar onde possam marcar o que fazem com os produtos. A uma produção racionalizada, expansionista além de centralizada, barulhenta e espetacular, corresponde outra produção, qualificada de 'consumo': esta é astuciosa, é dispersa, mas ao mesmo tempo ela se insinua ubiquamente, silenciosa e quase invisível, pois não se faz notar com produtos impostos por uma ordem econômica dominante (p. 39). 
Observamos que a produção e criação das crianças nesses momentos espontâneos traz uma dimensão potencializadora para a prática pedagógica. No entanto, esses produtos criados por elas se perdem, na medida em que não há lugares onde se possa demarcar essa produção. Com isso, destacamos a necessidade de criar um lugar de autoria, e que essas experiências sejam registradas, para, então, dar visibilidade ao modo como as crianças produzem diferentes formas de vivenciar o que é ser criança, sendo colocadas como protagonistas da sua própria formação e produtoras de cultura. Por meio do ato de registrar, apontamos uma possibilidade para o professor de Educação Física conduzir a sua ação docente, pois esses fazeres infantis, que geralmente passam no anonimato, podem se constituir em subsídios para orientar as suas práticas pedagógicas.

Nas práticas experienciadas pelas crianças em momentos espontâneos, percebemos que o jogo simbólico promove as relações sociais entre os pares, cria regras de convivência e medeia a produção cultural.

A seguir, analisaremos os jogos no contexto das aulas, em que há presença do professor de Educação Física. Nesse espaço, o jogo foi trabalhado, segundo classificação proposta por Caillois (1990), em dois polos: paideia e ludus. Caillois (1990) afirma que os jogos se situam entre dois polos de um mesmo continuum: em uma extremidade, há a paideia, em que predomina a diversão, o improviso, a turbulência e a fantasia; no outro extremo, o ludus, caracterizado por ações subordinadas às regras e aos obstáculos propostos pelo jogo, bem como pela organização, disciplina e controle.

Avaliamos, por meio das narrativas, que o professor privilegia jogos que transitam entre esses dois polos e que a rotina escolar influencia a sua definição. O Referencial Curricular Nacional para a Educação Infantil (Brasil, 1998) evidencia a importância que se atribui à rotina no cotidiano escolar. Ela deve ser orientadora da organização e do planejamento das práticas pedagógicas, dos processos de ensino-aprendizagem e dos cuidados higiênicos e físicos necessários ao atendimento das crianças. A rotina configura-se como espaço e tempo escolar, ou seja, as ações dos praticantes escolares são reguladas por meio da configuração da rotina, que deve ser planejada a partir das peculiaridades da infância e ser flexível de acordo com as diferenças individuais e com o tempo que a criança permanece na escola. 
Como podemos observar, a rotina se constitui como suporte para a construção dos planejamentos de aula e para a sua materialização. Percebemos que algumas aulas de Educação Física foram influenciadas pela rotina das crianças, que pode ser o horário do jantar, do pátio, da higienização e do descanso, e que o professor construiu seus planejamentos e suas ações de acordo com o tempo que ele dispunha.

Nos momentos em que a rotina reduz o tempo da aula, o professor planeja jogos com regras menos complexas e diretivas, que privilegiam características da paideia. Fragmentos extraídos do portfólio exemplificam a afirmação:

A atividade consistia em fazer bolhas de sabão. Os alunos demonstraram muita alegria em fazer as bolhas. Eles falaram que era legal e divertido. Naquele momento, observamos: crianças que faziam as bolhas e as estouravam, crianças que faziam as bolhas e queriam que elas fossem para o céu; e outras disputavam quem fazia a bolha maior [...] (DC, 18-11-2011 - Grupo 6).

A atividade consistia em descer a rampa do pátio, sentado, de skate. No início, todas as crianças fizeram a mesma coisa: pegaram o skate, sentaram e desceram a rampa. Depois, observamos algumas crianças descendo de diferentes maneiras no skate: de barriga para baixo, com os pés no chão, parando durante a descida [...] (DC, 28-11-2011 - Grupo 5).

O professor planeja atividades em que todas as crianças têm a oportunidade de participar simultaneamente. Por meio das análises, compreendemos que as expectativas das crianças foram ao encontro dos objetivos do professor. Elas compreenderam e aceitaram as regras e os sentidos dos jogos. Ao entender o que estava acontecendo, e devido ao fato de as tarefas não serem tão diretivas, as crianças passaram a ter oportunidades de participar com mais efetividade. Vivenciaram as práticas com prazer e alegria e contribuíram para a organização e direcionamento das brincadeiras, o que oportunizou ações criativas dos participantes.

Como estratégia de pesquisa, foi comum, após as aulas, nós brincarmos de entrevista para sabermos o que as crianças achavam das atividades. Pelas respostas das crianças nas entrevistas e pelas ações corporais observadas durante as aulas, percebemos que os modos de apropriação durante as atividades variam de usuário a usuário, e que os praticantes não são consumidores passivos, pois eles criam e recriam ao seu próprio modo o que lhes é apresentado (Certeau, 1994). 
Retomando a discussão da rotina, a pesquisa com o cotidiano nos fez repensar acerca do sentido negativo atribuído à configuração desse espaço $e$ tempo escolar, que há no interior das instituições de Educação Infantil. A princípio, existe a crença de que as aulas interrompidas pela rotina são desfavorecidas, pois o tempo do planejamento e o das ações são reduzidos, havendo uma diminuição de práticas sistematizadas. Mas, ao compartilhar o cotidiano, percebemos, em meio às complexas redes das práticas educacionais, que, nos momentos em que a rotina influenciou os planejamentos de Educação Física, as aulas foram ao encontro das expectativas das crianças. Foi oportunizado um tempo em que todas brincaram juntas e estabeleceram uma relação social entre pares e com 0 professor. As atividades oportunizaram espaços onde a criatividade emergisse, promovendo novas criações feitas pelas crianças, tornando-as sujeitos de direitos, que produzem cultura, o que favoreceu o seu protagonismo.

As apreciações realizadas com o cotidiano sobre as estruturações das aulas evidenciou o desafio de planejar a atuação em tempo reduzido e que, ao mesmo tempo, atendesse às expectativas dos alunos e do professor. As análises desse desafio se configuraram como possibilidades de materialização de uma práxis pedagógica que deu voz e vez às crianças nos processos de ensino-aprendizagem.

Contudo, quando a aula tem seu tempo integral, o professor planeja jogos mais complexos, que vão ao encontro do ludus, em que as regras explícitas delimitam o espaço de ações dos participantes (Piccolo, 2009), como pode ser observado nos fragmentos abaixo:

[...] o professor desenhou em um TNT um campo de futebol. No local dos gols, fez uma circunferência vazia. No momento em que a bola passasse pela circunferência e caísse ao chão, o gol seria marcado. As crianças, ao redor do TNT, foram dispostas seis para cada time, segurando o TNT pelas mãos. Elas teriam que fazer movimentos com os braços para a bola seguir em direção ao gol do seu time. No início do jogo, o professor frisou: 'O time de cá faz gol lá do outro lado; o time de lá faz gol aqui'. Iniciada a partida, as crianças balançavam euforicamente o TNT. Saiu o primeiro e o segundo gol e todas as crianças comemoraram (DC, 24-10-2011 - Grupo 5).

[...] explicação da atividade: o professor delimitou um espaço do pátio e colocou duas traves. Os alunos foram divididos em times com três pessoas cada. Cada criança do time ficou com um bastão e, com o auxílio dele, eles teriam que fazer 
gol no campo do adversário. A cada dois gols, trocavam os times. O professor iniciou relembrando as crianças que elas já haviam jogado este jogo. Perguntou se eles lembravam quais eram as regras. Algumas crianças falaram: 'Não pode pegar a bola com a mão'; 'Só pode jogar com este pau [...]'. O professor colocou três crianças para cada time. Na hora da execução da atividade, algumas crianças lembravam para que lado teriam que jogar a bola, já outras não, e o que importava para essas era o fato de encostar o taco na bola e a direcionar para o gol. Quando acontecia o gol era recorrente ver mais de três crianças em campo comemorando (DC, 25-11-2011 - Grupo 6).

Com base nas narrativas, foi possível estabelecer três eixos de análises em relação à organização pedagógica do professor: número de alunos por atividade, adequação das regras aos jogos e tempo de vivência.

$\mathrm{Na}$ forma como a aula foi organizada, percebemos que o número de crianças por atividade era reduzido. Com isso, algumas crianças participavam mais e outras menos dos jogos. Apesar de o tempo da aula ser integral, os infantis eram divididos em pequenos grupos, tendo assim um tempo de vivência de jogo menor do que quando a aula era influenciada pela rotina.

O motivo de o professor organizar as crianças em pequenos grupos está relacionado com a complexidade das regras, já que a maioria dos infantis não as compreendiam. Mediante essa dificuldade as crianças adequavam as atividades às suas necessidades. A realização da atividade não perpassava pelas regras em si, mas priorizava sua finalidade, como fazer o gol, e o prazer e a alegria em participar das aulas. Destaque deve ser dado à sensibilidade do professor em não interromper o jogo pelo fato de as crianças não estarem compreendendo as suas regras.

Mais uma vez, observamos os consumos produtivos operados pelas crianças em relação ao que é estrategicamente proposto nas aulas. As crianças modificavam as atividades adequando-as às suas necessidades, ou seja, elas agiam taticamente sobre as estratégias, criando, nos espaços astuciosos, outras possibilidades de viver o que foi orientado pelo professor. Entretanto, é preciso não apenas ter sensibilidade para deixar as crianças agirem sobre o que é ensinado, mas transformar as táticas produzidas pelos alunos em novas estratégias orientadoras para a prática docente em Educação Física.

Diante desse contexto, é preciso observar que "[...] o estudo das táticas cotidianas presentes não deve, no entanto, esquecer o horizonte de 
onde vem, nem tampouco, o horizonte para onde deveriam ir" (Certeau, 1994, p. 105). Nesse ponto, Carvalho (2009) salienta a necessidade de considerarmos a importância das táticas para possibilidade de implementar ou implodir a estratégia. Essa autora nos ajudou a entender que é nas operações táticas efetuadas dentro das estratégias que os praticantes vão criando outros lugares próprios, ou seja, transformando as táticas em novas estratégias. Assim, as táticas devem ser vistas como:

[...] campos de possibilidade de professores e alunos transcenderem a trajetória, transcenderem o lugar próprio de autoria individualizada rumo a um projeto estratégico/tático de criação coletiva contextualizada e problematizada, enfim, enraizada no princípio da comunidade (Carvalho, 2009, p. 169).

Quando concebemos as crianças como "sujeitos de direitos" e autoras de suas práticas sociais, o tempo do jogo é outro aspecto importante a ser considerado, ele ganha outra conotação. Deixa de ser cronos (relógio) e passa a ser kairos, ou seja, um tempo relacionado com o prazer, a satisfação que a pessoa tem em se relacionar com a atividade a que está submetida (Mello \& Damasceno, 2011). Dessa forma, a permanência ou a mudança de atividade não é mais determinada pelo tempo cronos, mas pelo envolvimento e pelo interesse que as crianças demonstram pelo jogo. Assim, um jogo pode durar uma aula ou, em uma aula, podem acontecer vários jogos.

Sarmento (2008) sinaliza que o protagonismo infantil deve ser fonte emergente na relação social escolar. De acordo com o autor, as "culturas infantis" - capacidade das crianças de construírem de forma sistematizada modos de significação do mundo - servem de referenciais para compreender a categoria geracional infantil, ou seja: para colocar a criança como participante nas complexas redes do cotidiano escolar, é necessário entender a cultura infantil, para integrá-las como protagonistas das atividades.

A cultura infantil é criada e recriada a partir da condição social, do contexto histórico em que a criança está inserida; entretanto, o jogo e as construções imaginárias são elementos que marcam essa cultura. Nesse sentido, os jogos e as brincadeiras, segundo a Lei de Diretrizes e Bases da Educação Nacional (Lei n. ${ }^{\circ}$ 9394, de 20 de dezembro de 1996), devem ser privilegiados nos espaços escolares da primeira infância.

Na perspectiva do protagonismo infantil, atribui-se ao jogo a conotação de mediar as relações sociais. Para isso, deve valorizar as formas 
espontâneas e voluntárias de jogo, assim como focalizar os diferentes jogos que elas trazem dos seus variados contextos de inserção social. Ao assumir essa postura, não se está negando a intencionalidade pedagógica da escola e nem a função de intervenção do professor, mas sinalizando que ambos (aluno e professor), de uma maneira diferenciada, fazem parte do processo ensino-aprendizagem.

Com base nos dados analisados neste estudo, compreendemos que uma prática pedagógica em educação da infância que se pretende mais respeitadora da criança precisa converter as 'pistas', nem sempre explícitas, dadas pelos infantis nas práticas cotidianas em procedimentos de ensino que valorizem as suas produções culturais. Para isso, as táticas empreendidas pelas crianças, ante as estratégias estabelecidas nas relações assimétricas de poder, precisam vir à tona e ganhar visibilidade, rompendo com uma cultura escolar adultocêntrica.

As 'pistas' encontradas neste estudo convergem com alguns pressupostos identificados por Sarmento (2004) para consolidar práticas pedagógicas que valorizam o protagonismo infantil. $O$ primeiro deles é a interatividade. As produções infantis, tanto nas situações espontâneas, como nas aulas de Educação Física, aconteceram, sobretudo, na "cultura de pares", denotando que o protagonismo infantil se manifesta com mais intensidade na ação coletiva. Uma pedagogia centrada no protagonismo das crianças deve compreender e valorizar o que se passa entre elas. Essas interações são potencializadas por meio de jogos e de brincadeiras que não sejam tão diretivos, permitindo que as crianças ajam com autonomia e criatividade, compartilhando experiências em suas produções culturais.

Outro pressuposto é a ludicidade. O protagonismo infantil se manifestou com maior frequência nos contextos em que as crianças transitam com mais competência, ou seja, nos ambientes lúdicos dos jogos e das brincadeiras. Dificilmente esse protagonismo ocorrerá em locais onde predomina a racionalidade do adulto. Entretanto, a ludicidade não é uma característica natural, intrínseca aos jogos e às brincadeiras, ela depende da relação subjetiva que as crianças estabelecem com essas atividades. Daí a necessidade de auscultar as crianças, ouvir os seus interesses, necessidades e expectativas em relação a essas manifestações da cultura lúdica infantil. Para isso, é preciso que os professores mobilizem diferentes linguagens, em 
especial a corporal, no trato com crianças que ainda não possuem uma linguagem verbal articulada.

A "fantasia do real" é outro pressuposto pedagógico que potencializa o protagonismo infantil e está relacionado à forma como as crianças pequenas representam simbolicamente o seu mundo, interagindo, simultaneamente, realidade e fantasia. Nos jogos de faz-de-conta, percebemos que as crianças atribuem outros significados aos objetos, não limitando a sua relação com o mundo à literalidade dos fatos. Elas internalizam e ressignificam papéis sociais, gerando reproduções interpretativas da cultura (Corsaro, 2011). Dentre as diferentes possibilidades de vivência dos jogos de faz-de-conta no contexto da Educação Infantil, destacamos as brincadeiras historiadas, em que, a partir de um roteiro, a brincadeira se desenvolve incorporando as impressões e criações das crianças.

Por fim, ressaltamos o tempo do jogo como pressuposto a ser observado na proposição de práticas pedagógicas centradas no protagonismo da criança. Dessa forma, o tempo de permanência ou de alteração em um jogo deve ser determinado pelo prazer, envolvimento e interesse da criança, e não pelo tempo cronos, previamente determinado para realização da atividade. Embora todos esses pressupostos apresentados focalizem o protagonismo infantil, eles só se materializarão a partir da mediação do professor, denotando o seu papel decisivo na condução de processos pedagógicos centrados nas crianças.

\section{Considerações finais}

O estudo analisou os usos e apropriações que crianças (cinco a seis anos) e professor fazem do jogo, em um CMEI de Vitória/Espírito Santo/Brasil. Para tanto, focalizou os pontos de convergência e divergência entre as expectativas dos praticantes, destacando o protagonismo infantil como princípio pedagógico. A apreciação contemplou duas dimensões em que o jogo se manifesta: em situações espontâneas e nas aulas de Educação Física.

Verificamos que as situações espontâneas se configuraram como tempos e espaços de criação dos alunos, em que há possibilidade de dar visibilidade às práticas desenvolvidas pelas crianças para, então, transformá- 
las em ações pedagógicas desenvolvidas pelos professores. Ao observar esses momentos de não aula, entendemos que o trato pedagógico do jogo deve acontecer pelo viés sócio-histórico (Vygotsky, 1994), pois vê o processo de mediação como produtor de interação social. Por meio dessa perspectiva, o professor, em sua prática, pode promover mediações que potencializem as competências argumentativas das crianças, possibilitando que elas se expressem sobre os jogos que preferem, sobre as formas que julgam mais interessantes para vivenciá-los, sobre as alterações e criações que desejam introduzir nos jogos para torná-los mais agradáveis. O professor deve ensinar novos jogos, não com a intenção de suprir as 'ausências' dos alunos, mas com o objetivo de ampliar as oportunidades de novas relações sociais e culturais para que as crianças tenham a possibilidade de materialização de uma atividade lúdica potencializada.

Ao mergulhar no cotidiano, observamos que o professor apresenta dois tipos de estruturas de planejamentos e de intervenção, que se distinguem pela influência que a rotina causa no tempo da aula. Quando os planejamentos e a intervenção não sofrem redução do tempo, a perspectiva que define as práticas parece não condizer com as necessidades da criança, fazendo com que as expectativas de alunos e professor se tornem divergentes. Contudo, as análises realizadas sobre as práticas vivenciadas quando o planejamento sofre redução do tempo mostraram-nos potencialidades que até então eram obscuras. Percebemos que as expectativas das crianças foram ao encontro da perspectiva do planejamento proposto pelo professor. À medida que as expectativas se tornaram convergentes, as crianças foram colocadas como protagonistas e sujeitos de direitos. A redução do tempo das aulas, provocada pela rotina, apresentou-se como um dispositivo positivo, caracterizando-se como possibilidade de uma práxis pedagógica que vai ao encontro dos interesses das crianças.

As análises empreendidas neste estudo reforçam a necessidade de construir novos instrumentos de pesquisas com as crianças, uma vez que elas podem ajudar a projetar outras práticas pedagógicas que atendam aos interesses e necessidades básicos da infância. 


\section{Referências}

Alves, N. (2008). Sobre os movimentos das pesquisas nos/dos/com os cotidianos. In I. B. Oliveira \& N. Alves (Orgs.), Pesquisa nos/dos/com os cotidianos das escolas (3 $3^{\text {a }}$ ed., pp. 39-48). Petrópolis: DP\&A.

Borba, M. (2009). Quando as criancas brincam de ser adultos: Vir-a-ser ou experiência da infância?. In J. Lopes \& M. Mello (Orgs.), O jeito que nós crianças pensamos sobre certas coisas: Dialogando com lógicas infantis (pp. 97-118) Rio de Janeiro: Rovelle.

Brasil (1998). Referencial nacional curricular para a educação infantil. Brasília: MEC/SEF.

Caillois, R. (1990). Os jogos e os homens: A máscara e a vertigem. Lisboa: Cotovia.

Carvalho, J. M. (2009). O cotidiano escolar como comunidade de afetos. Petrópolis, RJ: DP et Alii; Brasilia, DF: CNPq.

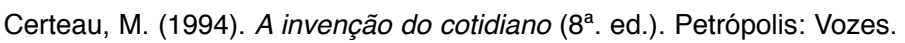

Corsaro, W. A. (2011). Sociologia da infância. Porto Alegre: Artmed.

Dahlberg, G., Moss, P., \& Pence, A. (2003). Qualidade na educação da primeira infância - Perspectivas pós-modernas. Porto Alegre: Artmed.

Ferraço, C. E. (2008). A pesquisa em educação no/do/com o cotidiano escolar. In C. E. Ferraço, C. L. V. Perez, \& I. B. Oliveira (Org.), Aprendizagens cotidianas com a pesquisa: Novas reflexões em pesquisa nos/dos/com os cotidianos das escolas. Petrópolis: DP et Alii.

Freire, J. (2002). O jogo: Entre o riso e o choro (2 ${ }^{\mathrm{a}}$. ed.). Campinas, SP: Autores Associados.

Gomes, E. S., \& Baumel, R. C. (2009). Corpo-movimento: Desafios das linguagens infantis para a educação. In Anais do $17^{\circ}$ COLE - Congresso de Leitura do Brasil. Campinas, SP, Brasil: ALB.

Mello, A., \& Damasceno, L. (2011). Conhecimento e metodologia do ensino do jogo. Vitória: Universidade Federal do Espírito Santo - Núcleo de Educação Aberta e Distância.

Mello, A., Santos, W., Votre, S. J., Klippel, M. V., \& Rosa, A. P. (2012). Desafios e possibilidades para a prática profissional da educação física na educação infantil. In A. Mello \& W. Santos (Orgs.), Educação física na educação infantil: Práticas pedagógicas no cotidiano escolar (pp. 93-104). Curitiba: CRV.

Neira, M. G. (2008) Educação física na educação infantil: Algumas considerações para a elaboração de um currículo coerente com a escola democrática. In N. F. Andrade Filho \& O. Schneider (Orgs.), Educação física para a educação infantil: Conhecimento e especificidade (pp. 45-96) São Cristovão: Editora UFS.

Piccolo, G. (2009). Jogo ou brincadeira: Afinal, de que estamos falando? Motriz, 15(4), 925-934.

Samaniego, V., Devis-Devis, J., Smith, B. M., \& Sparkes, A. C. (2011). La investigación narrativa en la educación física y el deporte: Qué es y para qué sirve. Movimento, 17(1), 11-38. .

Sarmento, M. (2004). As culturas da infância na encruzilhada da segunda modernidade. In M. Sarmento \& A. B. Cerisara (Orgs.), Crianças e miúdos: Perspectivas sociopedagógicas da infância e educação (pp. 9-34). Porto: Asa. 
Sarmento, M. J. (2008). Sociologia da infância: Correntes e confluências. In M. J. Sarmento \& M. C. S. Gouvea (Orgs.), Estudos da infância: Educação e práticas sociais (pp. 1-30) Petrópolis: Vozes.

Sarmento, M. J. (2013). A sociologia da infância e a sociedade contemporânea: Desafios conceituais e praxeológicos. In R. T. Ens \& M. C. Garanhani (Orgs.), Sociologia da infância e a formação de professores (pp. 13-46) Curitiba: Champagnat.

Sayão, D. T. (2002). Corpo e movimento: Notas para problematizar algumas questões relacionadas à educação infantil e a educação física. Revista Brasileira de Ciências do Esporte, 23(2), 55-67.

Silva, F. R., \& Maia, S. F. (2010). Narrativas autobiográficas: Interfaces com a pesquisa sobre formação de professores. In Anais do VI Encontro de Pesquisa em Educação - O Pensamento Pedagógico na Contemporaneidade. Tersina, Piauí, Brasil: PPGED/UFPI.

Vygotsky, L. S. (1994). A formação social da mente: O desenvolvimento dos processos psicológicos superiores ( $5^{\mathrm{a}}$. ed.). São Paulo: Martins Fontes.

\section{Legislação consultada}

Lei n. ${ }^{\circ}$ 9394, de 20 de dezembro de 1996. Brasília, DF. Dispõe sobre as diretrizes e bases da educação nacional. Disponível em http://www.planalto.gov.br/ ccivil_03/leis/19394.htm (consultado em 5 abril de 2010). 


\title{
GAME AND PROTAGONISM OF THE CHILD IN EARLY EDUCATION
}

\begin{abstract}
In this article, it is analyzed how children appropriate and use playful activities (games) in a Children's Education Center located in the city of Vitória/ES/Brazil, in order to understand the role they establish in the relations with such cultural forms of expression. To do so, the Studies with the Daily Life were used as a methodological assumption. Data was produced through narratives and participant observations, for a four-month period of school insertion. The analyzes reveal that the game is lived by children in spontaneous situations and, above all, in Physical Education classes. In the first case, the children organize their own practices, predominantly of symbolic games; whereas in the classes, they act tactically, altering the games proposed by teachers according to their interests and needs. In both cases, Vygotsky social-historical perspective and Certeau's concept of productive consumption highlighted the cultural production of the children in the relations they establish with the game, denoting its main role.
\end{abstract}

Keywords

Game; Physical Education; Children's education; Protagonism

\section{JEUX ET PROTAGONISME DES ENFANTS DANS LA PETITE ENFANCE}

\section{Résumé}

Dans cet article nous analysons les habitudes et les appropriations que les enfants prennent du jeu dans un Centre d'Éducation Infantile de Vitória/ES/Brésil pour comprendre le "protagonisme" qu'ils établissent dans les rapports ayant cette manifestation culturelle. Pour ce faire, nous avons utilisé les Études avec le Quotidien comme présupposé théorique/méthodologique. Les données ont été produites au moyen de narrations et d'observations de participants pendant quatre mois d'insertion 
dans l'école. Les analyses révèlent que le jeu est vécu par les enfants dans des situations spontanées et surtout dans les cours d'Éducation Physique. Dans le premier cas, les enfants organisent leurs propres pratiques avec l'ascendance des jeux symboliques; mais, lors des cours, ils agissent tactiquement, modifiant les jeux proposés par le professeur selon leurs intérêts et leurs besoins. Dans les deux cas, la perspective socio-historique, de Vygotsky, et le concept de consommation productive, de Certeau, ont mis en relief la production culturelle des enfants dans les rapports qu'ils établissent avec le jeu, marquant, par là, leur "protagonisme".

Mots-clé

Jeu; Éducation Physique; Éducation infantile; "Protagonisme"

Recebido em setembro/2014 Aceite para publicação em abril/2015

i Programa de Pós-Graduação do Centro de Educação Física e Desportos da Universidade Federal do Espírito Santo, Brasil.

ii Centro de Educação Física e Desportos, Instituto de Pesquisa em Educação e Educação Física - Proteoria, Universidade Federal do Espírito Santo, Brasil.

iii Centro de Educação Física e Desportos, Universidade Federal do Espírito Santo, Brasil.

iv Centro de Educação Física e Desportos, Instituto de Pesquisa em Educação e Educação Física - Proteoria, Universidade Federal do Espírito Santo, Brasil.

v Centro de Educação Física e Desportos, Instituto de Pesquisa em Educação e Educação Física - Proteoria, Universidade Federal do Espírito Santo, Brasil.

Toda a correspondência relativa a este artigo deve ser enviada para: Lívia Carvalho de Assis, Universidade Federal do Espírito Santo, Centro de Educação Física e Desportos, Av. Fernando Ferrari, 514, Campus Universitário, Goiabeiras - Vitório - ES, CEP: 29075810, Brasil. E-mail: livia.carvalhodeassis@gmail.com 